\title{
Current Trends and Challenges in Laboratory Investigation of the Covid-19 Pandemic
}

\author{
Protyusha Guha Biswas ${ }^{1}$, Logeswari J. ${ }^{2}$, Sathya Shankar ${ }^{3}$, Shyam S. ${ }^{4}$ \\ ${ }^{1}$ Assistant Professor, Department of oral Pathology and Microbiology, Faculty of Dentistry-Meenakshi Ammal \\ Dental College and hospital, Meenakshi Academy of Higher Education and Research, Chennai, ${ }^{2}$ Associate \\ Professor, Department of oral Pathology and Microbiology, Faculty of Dentistry-Meenakshi Ammal Dental College \\ and hospital, Meenakshi Academy of Higher Education and Research, Chennai, ${ }^{3}$ Assistant Professor, Department \\ of Prosthodontics, Faculty of Dentistry-Meenakshi Ammal Dental College and hospital, Meenakshi Academy of \\ Higher Education and Research, Chennai, ${ }^{4}$ Associate Professor, Department of Public Health Dentistry, Faculty \\ of Dentistry-Meenakshi Ammal Dental College and hospital, Meenakshi Academy of Higher Education and \\ Research, Chennai
}

\begin{abstract}
The ongoing virus impact in the whole world is COVID19 infection has led to unprecedented crisis paving to outrage of the world citizens. The highly contagious virus started its spread from the China during the month of late November 2019 and spread to all over the world. The COVID-19 pandemic led catastrophe and earlier episodes of similar epidemic SARS outbreaks in China and Middle East interrogate the preparedness in handling such predicament. The major symptomatic manifestations of patients are not so accurate and vary from one person to another and higher frequency of asymptomatic cases often misled diagnosis, unless the CT chest scan findings affirms the disease progress into fatal SARS. Disambiguation over the other viral respiratory illnesses similar to COVID-19 needs to be meticulously handled by emphasize on simultaneous co-detection of multiple viral pathogens. Henceforth, robust diagnostic tools are necessitated to substantiate suspected cases and to screen large population in less time. This review would keenly focus on the challenging prime requisite for accurate laboratory testing of the infection and the potentials of various techniques in investigating the pandemic.
\end{abstract}

Keywords: Combined ELISA, COVID-19, SARS2, N/S-IgM/IgG rapid card, Viral load.

\section{Introduction}

Novel Corona virus 2019 (nCoV) was a rapid spread and was officially identified by the Chinese Doctors and approved by CDC later, WHO declared pandemic emergency over the disease and outbreak rapidly started in the month of January 2020. The $2019 \mathrm{nCoV}$

\section{Corresponding Author:}

\section{Dr. Protyusha Guha Biswas}

Assistant Professor, Department of oral Pathology and Microbiology, Faculty of Dentistry-Meenakshi Ammal Dental College and hospital, Meenakshi Academy of Higher Education and Research, Chennai e-mail: drprotyusha.oralpathology@madch.edu.in was confirmed of the transmission from one person to another and the active infection were evidenced outside China ever since the outbreak, therefore warranting the cause for pandemic. As of October 2020 approximately 9,26,544 fatal cases were reported and over 29.2 crore people were infected with the viral pathogen. The government all over the world and as per the guidelines of WHO has stopped the travel to and fro overpandemic and lockdown periods getting extended in different countries leading to distress among the world citizens ${ }^{[1,2]}$.

The $\mathrm{nCoV}$ affects the respiratory system that can range from mild to fatal illness. Symptomatic cases shows high body temperature, wheeze, improper and difficulty in breathing, sore throat and diarrhea often undistinguished from other pathogenic pneumonias. According to $\mathrm{WHO}$ asymptomatic cases without any 
prompt signs and symptoms are the major threat to the healthcare workers by the way of spread ${ }^{[3]}$. The delayed and/or failure in probing of outbreak investigation would lead to extensive morbidity ${ }^{[4]}$. Here, our review focus on various means of testing and strategies for early, robust diagnosis in handling the global emergency.
The chronicles of Corona virus's family: Corona viruses (CoVs) are the large, pleomorphic, positive sense ssRNA virus with $26-32 \mathrm{kbp}$ genome encapsulated in a helical symmetry nucleocapsid $(\mathrm{N})$ protected by an outer envelope (E) with surface characteristics of clubshaped spike (S) and hemagglutinin esterase.

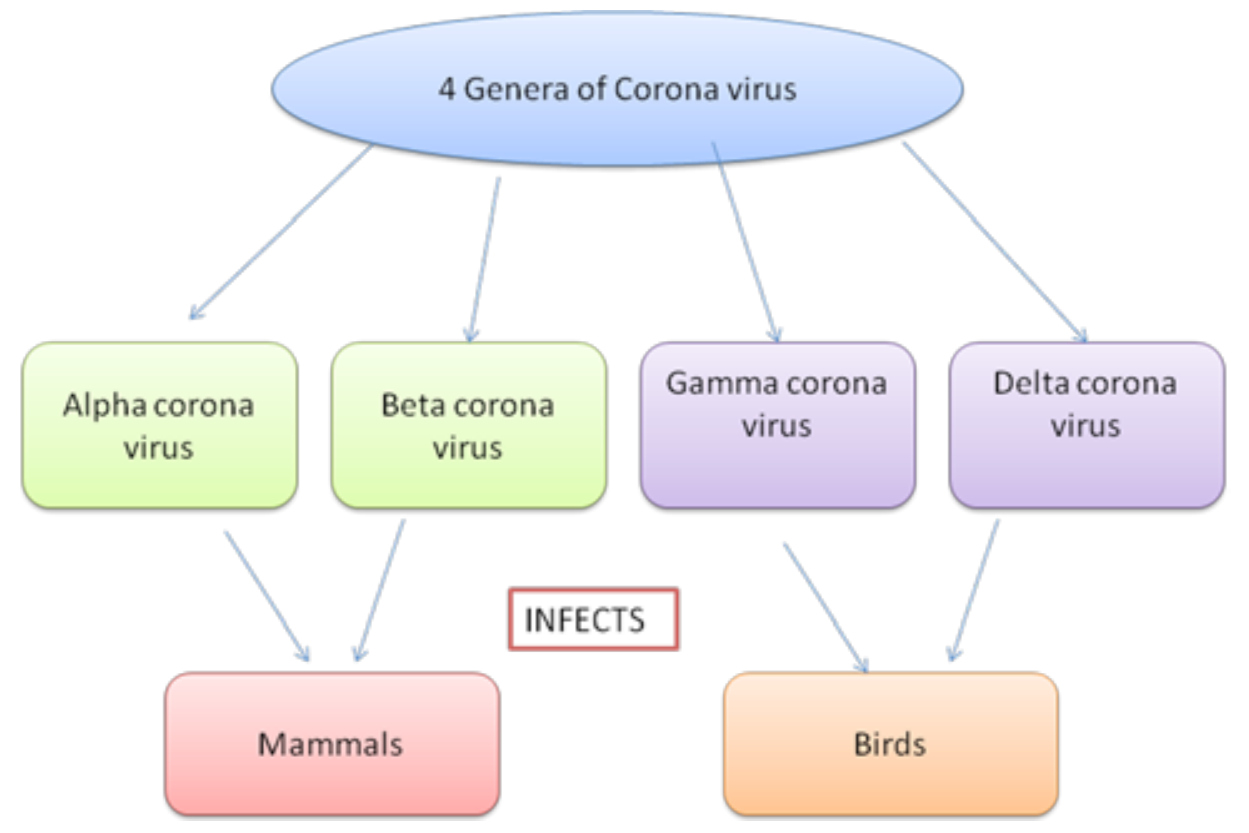

Fig. 1. Categories of Corona virus ${ }^{[5]}$

Ancestrally, the CoV family infects many eukaryotes especially mammals and avian species, very few strains of the CoV family are circulating among humans causes acute respiratory infections. Genomic analysis of the virus revealed $89 \%$ and $82 \%$ of nucleotide similarity with bat represent the virus as SARS-like-CoVZXC21 and human SARS-CoV respectively and $40 \%$ amino acid identity matched with the peripheral sub domain of the spike's present in the virus acts as receptor binding domain [6]. Historically, 2002-2003 major epidemic outbreaks in China due to SARS-CoV originating in bats were reported of significant mortality ${ }^{[3]}$.

COVID-19 manifestations and clinical diagnosis: ARD associated with the respiratory Syncytial virus, parainfluenza viruses, metapneumovirus, and CoVs, are hugely uncovered. Understanding the SARS-CoV-2 pathogenesis is imperative in drafting guidelines for screening COVID-19 at the earliest. The clinical variety of infection varies from without symptomatic forms to fatal sepsis and multiorgan dysfunction ${ }^{[9]}$. Fever (88\%), dry cough (68\%) are mainly the general signs of infection; other non-specific symptoms are also present in the infected person from mild fatigue, to other respiratory viral infections ${ }^{[4]}$. Radiographic chest examination during the early COVID-19 presents multiple plaques, changes in the lung margins and as infection develops severity it leads to ground-glass opacities, lung consolidation, and cardiac injury depicting the cardinal signs of ARD as reported by WHO. Another Scientist identified that the infection was related with inflammation in brain of humans with the pathogens RNA sense in cerebrospinal fluid (CSF). Following, Poyiadji et al stated a similar case study with immune mechanism where acute necrotizing encephalopathy is a type of post-infection ${ }^{[10]}$.

The sHLH is a respiratory infections caused by $\mathrm{hCoVs}$ and its salient feature of $\mathrm{sHLH}$ include hypercytokinaemia, cytopenias, hyperferritinaemia, and blood clots leading to vascular inflammation, thromboembolism, hypotensive shock with multiorgan failure [11]. Garcia et al studied several other bodily 
dysfunctions were positively combined, with the death rate and inverse proportionate with $\mathrm{P} / \mathrm{F}$ ratio. The acute cardiac injury in COVID-19 cases is diagnosed with flanking serum levels of cardiac biomarkers or from abnormalities in recorded in ECG. The blood profile of the COVID-19 cases reveals eosinopenia, creatine kinase, procalcitonin, elevated lymphocytes, and elevated markers for inflammation are interleukin-6, erythrocyte sediment rate and others ${ }^{[4,12]}$. The concurrent recognition of dual biomarker is protein A resistant against Myxovirus, CRP test identifies host immune response and also facilitates viral and bacterial acute respiratory illnesses differentiation ${ }^{[13]}$. These auxiliary findings help the physician in evaluating prognosis of COVID-19 cases upon treatment and in epidemiological surveillances.

Laboratory testing of COVID-19: According to the WHO recommendations the laboratory requisite should follow up based on the evidence of epidemiological history, clinical manifestations fulfilling criteria for case suspect definition. Unlikely the typical COVID-19 manifestations are misleading, therefore auxiliary screening of immune components and quantification of pathogen nucleic acid by RT-qPCR is empirical ${ }^{[2,9]}$. The immune response to CoVs follows a production of antibodies IgM and IgG specifically associated with similar viral respiratory tract infections. In the presence of viral load IgM antibodies vanish at $12^{\text {th }}$ week, while $\operatorname{IgG}$ antibody lasts long playing a protective role and specific titer varies during the acute and convalescent phase. The antibodies against the virus are activated after few weeks of infection ${ }^{[14,15]}$. Simultaneous likely evaluation of prognostic seromarker included complete haemogram, renal function, liver enzymes profile, creatine kinase, lactate dehydrogenase, electrolytes, CRP, myocardial enzymes, cardiac troponin I, Coagulopathy profile like ferritin are valuable in periodical assessment of the severity and recovery from the disease ${ }^{[12]}$.

Clinical specimens: $\mathrm{WHO}$ and $\mathrm{CDC}$ recommend clinical laboratories handling COVID-19 patient samples with the potential to generate aerosols need to practice standard precautions within a Class II Biosafety Cabinet (BSC) facility to prevent transmission in healthcare settings. Use of appropriate personnel protective equipment, precautions for droplet/aerosol generating specimen must be exactingly adapted. Laboratories performing live SARS-CoV-2 propagation and/or isolation, handling large volumes of infectious samples should strictly execute in no less than a BSC-3 milieu ${ }^{[16]}$. Occurrence of high viral infection in upper and lower respiratory tracts have been reported and therefore sampling the respiratory specimens within 5-6 days of the infection pneumonic symptoms facilitates accurate diagnosis ${ }^{[17]}$. Zhou observed longer duration of viral infection people for up to 37 days, apart from these, infection is also detected from fecal deposits, urine sample and blood, but less effect compared with respiratory specimens ${ }^{[18]}$. Investigation utilizing open reading frame $1 a b$ gene specific RT-qPCR in quantifying the virus in assessment of shedding pattern in 1070 specimens revealed $93 \%$ bronchoalveolar lavage fluid (BALF) were positive, followed by other parameters showed a negative result ${ }^{[19]}$. In clinical suspects single respiratory specimen does not eliminate the analysis, testing the respiratory tracks are recommended ${ }^{[9]}$.

URT samples are simple method to collect and therefore frequency of testing patients with mild symptoms, and can be easily implemented in resource limited settings ${ }^{[9]}$. Reportedly, the swabs from oral pharynx region was more accurate than nasal pharynx specimens; however, the pathogens RNA present in Oral specimen was comparatively least than positive Nasal specimens (63\%). CDC advise labs to collect the URT-NP swab and OP swab is a least priority, and if collected also the samples should be mixed with the NP swab and transported in viral transport medium ${ }^{[19]}$. For the most sensitive detection of virus BALF is suggested as the collection of mucus from lower airways but this increases the chance of biosafety risk to healthcare workers.

Viral RNAemia is chiefly warranted in COVID-19 and therefore along with blood sampling- fecal, urine, stool samples investigations are vital in understanding the pathogenesis and route of transmission ${ }^{[20]}$. Seminal fluid collected from 34 recovering adult Chinese male were tested negative and the expression profile of the enzyme angiotensin- 2 and integral membrane enzyme serine protease 2 within the male reproductive gland testicles showed no significant results ${ }^{[17]}$.

SARS-CoV-2 cultivation: The techniques involved in viral cultivation are by Cell culture and nucleic acidbased tests to respiratory viral infections. The viral shedding in the URT secretions are ideal for pathogen recovery, however the viral specimens varies with the viral pathogenesis ${ }^{[19]}$. The bacterial infection in lungs is identified with blood cultures in corona positive patients cases were $6.9 \%$ and specific species were also found in 
$45.8 \%$ of corona patients with Mycoplasma pneumoniae, Haemophilus influenza, and Pseudomonas aeruginosa infections ${ }^{[21,22]}$. Pyrc et al showed that separation and categorization of $\mathrm{HCoVs}$. For several respiratory viruses the epithelial border has been determined via HAE cultures ${ }^{[23]}$. Harcourt et al isolated SARS-CoV-2 from NP and OP specimens by cultivating in Vero cells and evaluated the cytopathic effect using standard plaque assay ${ }^{[24]}$. The presence of virus was also detected in saliva test patients $(91.7 \%)$ by RT-qPCR and the load was determined to be $3.3 \times 10^{6}$ copies $/ \mathrm{ml}$ when cultivated on Vero E6 ${ }^{[25]}$.

\section{Immunodiagnostic method for COVID-19 testing:}

Rapid screening test: Rapid COVID-19 testing kits designed based on lateral flow immunoassay are of diagnostic importance in cost-effective screening during acute phase of infection thereby reducing the need for molecular confirmatory tests in large-scale epidemiological surveillance. COVID-19 rapid card tests are detects specific viral antigens $\mathrm{E}, \mathrm{S}, \mathrm{N}$ and/or specific antibodies in the respiratory and serum samples. The immunochromatographic assay was reported to detect antibodies in the patients were $43.6 \%$ suspected cases tested negative for viral RNA ${ }^{[26]}$. The comparative sensitivity of three techniques that included $\mathrm{IgG} /$ IgM ELISA, colloidal gold-immunochromatographic assay and RT-qPCR in testing COVID-19 revealed no significant differences ${ }^{[27]}$. The combined test method has $88.66 \%$ sensitivity and specificity of $90.63 \%$. However, there results were still remain false being dependent on the serum level of antibodies and the phase of immune reaction ${ }^{[28]}$.

In a similar comparative investigation on the combinatorial detection of viral strain $\operatorname{IgM}$ and $\operatorname{IgG}$ using immunochromatographic strip along with RTqPCR. Pseudopositive results incurred may be due to sharing of similar epitope with the others members of the CoV family, and other viral etiology of common cold. However, these misinterpretations can be averted with the use of antibody probes which are monoclonal in nature, and the other CoVs are not traced to be circulating in the recent times ${ }^{[29]}$. Combination of viral RNA and specific antibody identification by rapid testing, even in early phase of onset. In exceptional cases, the RTqPCR confirmed COVID-9 patients exhibiting weak, late or absence of antibody responses. The majority of patients develop rapid antibody testing can be validated chiefly in the recovery phase. Several commercial rapid card kits available in the global market are designed feasibly for screening the viral antigens present in the respiratory specimens. Antigen screening kits are useful in evaluating early exposure ahead of onset of clinical symptoms ${ }^{[30]}$.

Enzyme Linked Immunosorbent Assay (ELISA): The viral antigen or specific antibody is of prognostic value in quantitative assessment of immune system of the diseased host. The combined viral nucleocapsid protein specific IgM/IgG ELISA showed lesser false-positives with IgG detection compared to single antibody assays [28]. In investigating the nucleocapsid and spike based testing for antibodies in identified cases revealed $80.4 \%$ and $82.2 \%$ positive rates for anti-N and anti-S SARS$\mathrm{CoV}-2$ antibodies and the increase in cases as the days are prolonged ${ }^{[30]}$. The virus enter into the target cell with the help of glycoprotein present in spike, which dilutes the antibodies upon URT infection; IgA specific ELISA are useful in early screening. Perera et al developed spike protein from the viral strain as a receptor-binding domain IgG/IgM ELISA with sensitivity and specificity comparative to microneutralisation and $90 \%$ plaque reduction neutralization tests ${ }^{[31]}$. However, the utility of ELISA in testing of COVID-19 is restricted to sophisticated laboratories as the protocols are heavily laborious and are time consuming.

Chemiluminescence immunoassay (CLIA): Luminogen based chemiluminescence assay for the identification of anti-viral nucleocapsid antibody was formed by Lin et al utilizing the recombinant full length nucleocapsid antigens mixed to the tosyl magnetic beads incubated with the test serum and analyzed in an automated chemical immunoluminescence analyzer. In this method 14 persons were reported to be positive cases $(21 \%)$ but they are negative and this was identified for antibody testing by ELISA and chemiluminescence assays. Cai et al developed magnetic CLIA specific to $\mathrm{ORF} 1 \mathrm{a} / \mathrm{b}, \mathrm{S}$, and $\mathrm{N}$ proteins for detecting the target antibodies against the virus. Compared to the ELISA kit, chemiluminescence assay showed more promising results ${ }^{[32]}$.

\section{Conclusion}

The contagious spread of the virus demands high processing; the clinical laboratory investigation played the major defensive role to seclude victims away from calamitous COVID-19 pandemic. The accuracy of 
laboratory reporting are influenced by a number of interrelated factors such as virus shedding, time period of specimen collection, viral load titers, host immune response and age predicts the diagnostic sensitivity of the laboratory testing. Adding to the low level of testing centers and inadequacy of trained professional is worrisome inflating the health care workers and the public spread is postponed due to isolation of the probable missed cases leading to community spread. These challenging variants in the screening and confirmation of SARS-COV-2 infections define the interdisciplinary secular path for coherent laboratory testing to the necessity of standard clinical practices. The corona virus and other viral infections associated physiological changes (heart rate, $\mathrm{SpO} 2$ ) which are potential indicators can be monitored using wearable sensors (Apple, WHOOP watches) would be of prognostic value. The future directions leading the mankind in handling such pandemic would be the progress in scientific learning on the advanced diagnostic technologies.

\section{Ethical Clearance: Nil}

Source of Funding: Meenakshi Academy of Higher Education and Research, Chennai, India

\section{Conflict of Interest: Nil}

\section{References}

1. Holshue ML, DeBolt C, Lindquist S, Lofy KH, Wiesman J, Bruce H, Spitters C, Ericson K, Wilkerson S, Tural A, Diaz G. First case of 2019 novel coronavirus in the United States. New England Journal of Medicine. 2020 Jan 31.

2. Huang C, Wang Y, Li X, Ren L, Zhao J, Hu Y, Zhang L, Fan G, Xu J, Gu X, Cheng Z. Clinical features of patients infected with 2019 novel coronavirus in Wuhan, China. The lancet. 2020 Feb 15;395(10223):497-506.

3. Report of the WHO - China Joint Mission on Coronavirus Disease 2019 (COVID-19). WHO. https://www.who.int/docs/default-source/ coronaviruse/who-china-joint-mission-on-covid19-final-report.pdf; 2020.

4. Kampf G, Todt D, Pfaender S, Steinmann E. Persistence of coronaviruses on inanimate surfaces and their inactivation with biocidal agents. Journal of Hospital Infection. 2020 Mar 1;104(3):246-51.

5. Wu X, Cai Y, Huang X, Yu X, Zhao L, Wang F, Li Q, Gu S, Xu T, Li Y, Lu B. Co-infection with
SARS-CoV-2 and influenza A virus in patient with pneumonia, China. Emerging infectious diseases. 2020 Jun;26(6):1324.

6. Wang Y, Sun J, Zhu A, Zhao J, Zhao J. Current understanding of middle east respiratory syndrome coronavirus infection in human and animal models. Journal of thoracic disease. 2018 Jul;10(Suppl 19):S2260.

7. Cascella M, Rajnik M, Cuomo A, Dulebohn SC, Di Napoli R. Features, evaluation and treatment coronavirus (COVID-19). InStatpearls [internet] 2020 Mar 8. StatPearls Publishing.

8. Moriguchi T, Harii N, Goto J, Harada D, Sugawara H, Takamino J. \& Nakao, A.(2020). A first case of meningitis/encephalitis associated with SARSCoronavirus-2. International Journal of Infectious Diseases.

9. Zhang W, Du RH, Li B, Zheng XS, Yang XL, Hu B, Wang YY, Xiao GF, Yan B, Shi ZL, Zhou P. Molecular and serological investigation of 2019$\mathrm{nCoV}$ infected patients: implication of multiple shedding routes. Emerg Microbes Infect. 2020; 9 (1): 386-9.

10. Poyiadji N, Shahin G, Noujaim D, Stone M, Patel S, Griffith B. COVID-19-associated acute hemorrhagic necrotizing encephalopathy: CT and MRI features. Radiology. 2020 Mar 31:201187.

11. Sun Y, Dong Y, Wang L, Xie H, Li B, Chang C, Wang FS. Characteristics and prognostic factors of disease severity in patients with COVID-19: The Beijing experience. Journal of Autoimmunity. 2020 Apr 24:102473.

12. Pulia MS, O’Brien TP, Hou PC, Schuman A, Sambursky R. Multi-tiered screening and diagnosis strategy for COVID-19: a model for sustainable testing capacity in response to pandemic. Annals of Medicine. 2020 Apr 30(just-accepted):1-20.

13. World Health Organization. Laboratory testing for 2019 novel coronavirus (2019-nCoV) in suspected human cases, Interim guidance, 2 March 2020.

14. Zhao J, Yuan Q, Wang H, Liu W, Liao X, Su Y, Wang X, Yuan J, Li T, Li J, Qian S. Antibody responses to SARS-CoV-2 in patients of novel coronavirus disease 2019. Clinical Infectious Diseases. 2020 Jan 1.

15. Iwen PC, Stiles KL, Pentella MA. Safety considerations in the laboratory testing of specimens suspected or known to contain the severe 
acute respiratory syndrome coronavirus 2 (SARSCoV-2). American Journal of Clinical Pathology. 2020 Apr 15;153(5):567-70.

16. Pan F, Xiao X, Guo J, Song Y, Li H, Patel DP, Spivak AM, Joseph PA, Zhang X, Xiong C, Li PS. No evidence of SARS-CoV-2 in semen of males recovering from COVID-19. Fertility and sterility. 2020 Apr 17.

17. Zhou F, Yu T, Du R, Fan G, Liu Y, Liu Z, Xiang J, Wang Y, Song B, Gu X, Guan L. 530 Y. Wei, H. Li, X. Wu, J. Xu, S. Tu, Y. Zhang, H. Chen, B. Cao, Clinical course and risk factors for mortality of adult inpatients with COVID-19 in Wuhan, China: a retrospective cohort study, Lancet. 2020;395:105462.

18. Wang $\mathrm{W}, \mathrm{Xu} \mathrm{Y}$, Gao R, Lu R, Han $\mathrm{K}, \mathrm{Wu} \mathrm{G}$, Tan W. Detection of SARS-CoV-2 in different types of clinical specimens. Jama. 2020 May 12;323(18):1843-4.

19. Huang P, Liu T, Huang L, Liu H, Lei M, Xu W, Hu $\mathrm{X}$, Chen J, Liu B. Use of chest CT in combination with negative RT-PCR assay for the 2019 novel coronavirus but high clinical suspicion. Radiology. 2020 Apr;295(1):22-3.

20. Sepulveda J, Westblade LF, Whittier S, Satlin MJ, Greendyke WG, Aaron JG, Zucker J, Dietz D, Sobieszczyk M, Choi JJ, Liu D. Bacteremia and Blood Culture Utilization During COVID-19 Surge in New York City. Journal of Clinical Microbiology. 2020 May 13.

21. Langford BJ, So M, Raybardhan S, Leung V, Westwood D, MacFadden DR, Soucy JP, Daneman $\mathrm{N}$. Bacterial co-infection and secondary infection in patients with COVID-19: a living rapid review and meta-analysis. Clinical Microbiology and Infection. 2020 Jul 22.

22. Pyrc K, Sims AC, Dijkman R, Jebbink M, Long C, Deming D, Donaldson E, Vabret A, Baric R, Van Der Hoek L, Pickles R. Culturing the unculturable: human coronavirus HKU1 infects, replicates, and produces progeny virions in human ciliated airway epithelial cell cultures. Journal of virology. 2010 Nov 1;84(21):11255-63.

23. Harcourt J, Tamin A, Lu X, Kamili S, Sakthivel SK, Murray J, Queen K, Tao Y, Paden CR, Zhang J, Li $\mathrm{Y}$. Severe acute respiratory syndrome coronavirus 2 from patient with coronavirus disease, United States. Emerging infectious diseases. 2020
Jun;26(6):1266.

24. To KK. W, Tsang OT-Y, Leung W-S, et al. Temporal profiles of viral load in posterior oropharyngeal saliva samples and serum antibody responses during infection by SARS-CoV-2: an observational cohort study. Lancet Infect Dis. 2020;20(5):565-74.

25. Pan Y, Li X, Yang G, Fan J, Tang Y, Zhao J, Long X, Guo S, Zhao Z, Liu Y, Hu H. Serological immunochromatographic approach in diagnosis with SARS-CoV-2 infected COVID-19 patients. Journal of Infection. 2020 Apr 10.

26. Woo PC, Lau SK, Wong BH, Tsoi HW, Fung AM, Kao RY, Chan KH, Peiris JM, Yuen KY. Differential sensitivities of severe acute respiratory syndrome (SARS) coronavirus spike polypeptide enzyme-linked immunosorbent assay (ELISA) and SARS coronavirus nucleocapsid protein ELISA for serodiagnosis of SARS coronavirus pneumonia. Journal of clinical microbiology. 2005 Jul 1;43(7):3054-8.

27. Calucho E. Lateral flow devices for COVID-19related biomarkers. Biosensors for pandemics May 06, 2020. 2020:29.

28. Liu W, Liu L, Kou G, Zheng Y, Ding Y, Ni W, Wang Q, Tan L, Wu W, Tang S, Xiong Z. Evaluation of nucleocapsid and spike protein-based enzyme-linked immunosorbent assays for detecting antibodies against SARS-CoV-2. Journal of clinical microbiology. 2020 May 26;58(6).

29. Liu Y, Liu Y, Diao B, Ren F, Wang Y, Ding J, Huang Q. Diagnostic Indexes of a Rapid IgG/ IgM Combined Antibody Test for SARS-CoV-2. medRxiv. 2020 Jan 1.

30. Loeffelholz, M.J. and Tang, Y.W., 2020. Laboratory diagnosis of emerging human coronavirus infections-the state of the art. Emerging microbes $\&$ infections, 9(1), pp.747-756.

31. Cai X, Chen J, Hu J, Long Q, Deng H, Fan K, Liao P, Liu B, Wu G, Chen Y, Li Z. A Peptidebased Magnetic Chemiluminescence Enzyme Immunoassay for Serological Diagnosis of Corona Virus Disease 2019 (COVID-19). medRxiv. 2020 Jan 1.

32. Liu R, Han H, Liu F, Lv Z, Wu K, Liu Y, Feng $\mathrm{Y}$, Zhu C. Positive rate of RT-PCR detection of SARS-CoV-2 infection in 4880 cases from one hospital in Wuhan, China, from Jan to Feb 2020. Clinica Chimica Acta. 2020 Mar 7. 